\title{
Report and investigation model of WeChat popularization in China's colleges and universities in 2015
}

\author{
Li You-Hong, Wang Ru, Lu Xing-Hua, Wang Xue-Jun, Zhu Jie \\ HuaLi College Guangdong University of Technology \\ Guangzhou, China
}

\begin{abstract}
Based on China's colleges and universities are the different types of 267136 questionnaire data, as well as acquisition simulator WeChat grabbed to nearly 2GB of data, as well as the tertiary education sector keyword data collection, as well as domestic colleges and universities to provide authoritative body ranking WeChat collection of data. Then the data collected by the authors of the word design clustering survey model modeling analysis, given China's colleges and universities WeChat universal status reports. The report found that in China's colleges and universities using WeChat is already a way of life, the high viscosity user WeChat, dependencies, colleges and universities of vermicelli WeChat public rational structure, information dissemination of efficiency. Report data can be used as a digital campus building in colleges and universities, and management.
\end{abstract}

Keywords-WeChat popularity of colleges and universities; WeChat universal model; colleges and universities WeChat application

\section{INTRODUCTION}

According to the July 2015 CNNIC 36th Internet development in China Statistics report shows the size of Internet users in the PRC: 668 million Internet users, mobile phone, the scale of 594 million, use the mobile phone to access the Internet, the ratio of $88.9 \%{ }^{[8]}$.It was also in October 2015 issued by the Tencent-reading of the report of the user data WeChat the correct posture to a text display: April Login
User 5.7 billion each WeChat account number in the user groups of the WeChat active" the highest peak is 10 per night spots, the daily per capita WeChat call time in minutes, 15 29 0.7 year-olds for a total of about 280 million, young people of the WeChat coverage rate of about $90 \%{ }^{[9]}$. In China it is already a WeChat lifestyles.

In recent years the pace of higher education than other WeChat user industry, its user in proportion to the numbers of viscosity, and dependence on level is higher than other industries in the area. In China on the report of the statistical WeChat although there as well as Iresearch, Tencent, CNNIC version, but this several agencies are for National Statistics, User WeChat no WeChat of colleges and universities popularity of statistics. Colleges and universities in order to get the community aware of the managers and the largest WeChat user groups, the popularity of colleges and universities WeChat condition surveys have become very urgent and important.

\section{THE DESIGN OF SURVEY MODEL}

\section{A. Object of the questionnaire}

Users: China's university WeChat operators, College students, Graduate, University administrators, Parents of students, Teaching management institution, Cooperative units and other.

\begin{tabular}{|c|c|c|c|c|c|c|c|c|c|c|c|c|c|}
\hline \multirow[b]{2}{*}{ School level } & \multirow[b]{2}{*}{ object } & \multicolumn{3}{|c|}{ Enrolment student } & \multicolumn{5}{|c|}{ Educational Personnel } & \multicolumn{2}{|c|}{ Parents of students } & \multicolumn{2}{|c|}{ other } \\
\hline & & $\begin{array}{c}\text { Enrolme } \\
\text { nt(1) }\end{array}$ & $\begin{array}{l}\text { question } \\
\text { naire(2) }\end{array}$ & $\begin{array}{l}\text { Recyclin } \\
\text { g }\end{array}$ & $\begin{array}{l}\text { Schoo } \\
\text { ls(3) }\end{array}$ & $\begin{array}{l}\text { manage } \\
\text { ment (4) }\end{array}$ & $\begin{array}{l}\text { Recyc } \\
\text { ling }\end{array}$ & $\begin{array}{l}\text { Teach } \\
\text { er (5) }\end{array}$ & $\begin{array}{c}\text { Recyc } \\
\text { ling }\end{array}$ & $\begin{array}{l}\text { question } \\
\text { naire }\end{array}$ & Recycling & $\begin{array}{l}\text { question } \\
\text { naire@6 }\end{array}$ & $\begin{array}{l}\text { Recy } \\
\text { cling }\end{array}$ \\
\hline & state-run & 13512598 & 270252 & 108101 & 796 & 637 & 509 & 13513 & 8108 & 1351 & 405 & 398 & 131 \\
\hline $\begin{array}{l}\text { Normal } \\
\text { Courses }\end{array}$ & Non-government & 1055119 & 21102 & 8441 & 141 & 113 & 90 & 1055 & 633 & 106 & 32 & 71 & 23 \\
\hline And above & $\begin{array}{l}\text { Independent } \\
\text { Institutions }\end{array}$ & 2690625 & 53813 & 21525 & 275 & 220 & 176 & 2691 & 1614 & 269 & 81 & 138 & 45 \\
\hline Short-cycle & state-run & 7943543 & 158871 & 63548 & 1028 & 822 & 658 & 7944 & 4766 & 794 & 238 & 514 & 170 \\
\hline Courses & Non-government & 2122803 & 42456 & 16982 & 306 & 245 & 196 & 2123 & 1274 & 212 & 64 & 153 & 50 \\
\hline Adult HEIs & Society niversity & 6531212 & 130624 & 52250 & 292 & 234 & 187 & 6531 & 3919 & 653 & 196 & 146 & 48 \\
\hline Other & Other & 1730588 & 34612 & 13845 & 7 & 6 & 4 & 1731 & 1038 & 173 & 52 & 4 & 1 \\
\hline Total & & 35586488 & 711730 & 284692 & 2838 & 2276 & 1821 & 35586 & 21352 & 3559 & 1068 & 1423 & 469 \\
\hline Recycling & & & & 284692 & & & 1821 & & 21352 & & 1068 & & 469 \\
\hline Qualified & & & & 261917 & & & 1785 & & 20498 & & 961 & & 375 \\
\hline
\end{tabular}

Identify applicable sponsor: Major scientific research project of Guangdong colleges and Universities, China. 
WeChat platform : University official WeChat public platform, China Youth Daily WeChat official public platform, Southern Weekend official WeChat public platform and other.

Time of survey: May 1, 2015 -2015 November 31st

\section{B. Distribution of the questionnaire}

Distribution of the questionnaire: As shown in Table 1: Referring to the February 26, 2015 National Bureau of statistics 2014 national economic and social development statistics bulletin tenth Distribution Survey ${ }^{[1]}$, Proportion of design questionnaire: Graduate student / Undergraduate and College Students $=1 / 14$. Refer to the Ministry of education in 2015, the national higher school list data ${ }^{\text {[2] }}$,Distribution of College scale. Referring to the Ministry of Education announced the 2014 Education Statistics [3], Distribution of student sample. Questionnaire design scale:(2)=(1)*0.02,(4)=(3)*0.8,(5)=(1)/20,(6)=(3)*0.5.

\section{Data collecting:}

- This paper uses the (WeChat ID: zqbcyol), the Southern Weekend (WeChat ID: nanfangzhoumo) within 3 months of the National College WeChat Official Accounts list of the top 100 of the list of all the WeChat article title.
- WeChat Official Accounts user replies and interface call data set, this paper collected the typical sample of the HuaLi College Guangdong University of Technology official WeChat data.

\section{Questionnaire controling}

The operator, the community are using paper questionnaires. The students' questionnaire was used to investigate the cooperation between the school and the official WeChat and micro blog. In addition, the use of artificial collection of 500 different types of universities in the official WeChat menu and functional data. Website, micro blog, WeChat survey, so that each IP address and an account can only participate in a survey. SPSS check and retreatment for all the questionnaires.

\section{Survey model and experiment testing}

\section{1) Report take shape into model}

As shown in Figure 1, the reliability of all questionnaires will be processed by the model, and the data set is processed by word segmentation and clustering data mining. After treatment, the WeChat user status report, the report can provide help for the university management and University Digital Campus onstruction.

Figure 1 report formation model

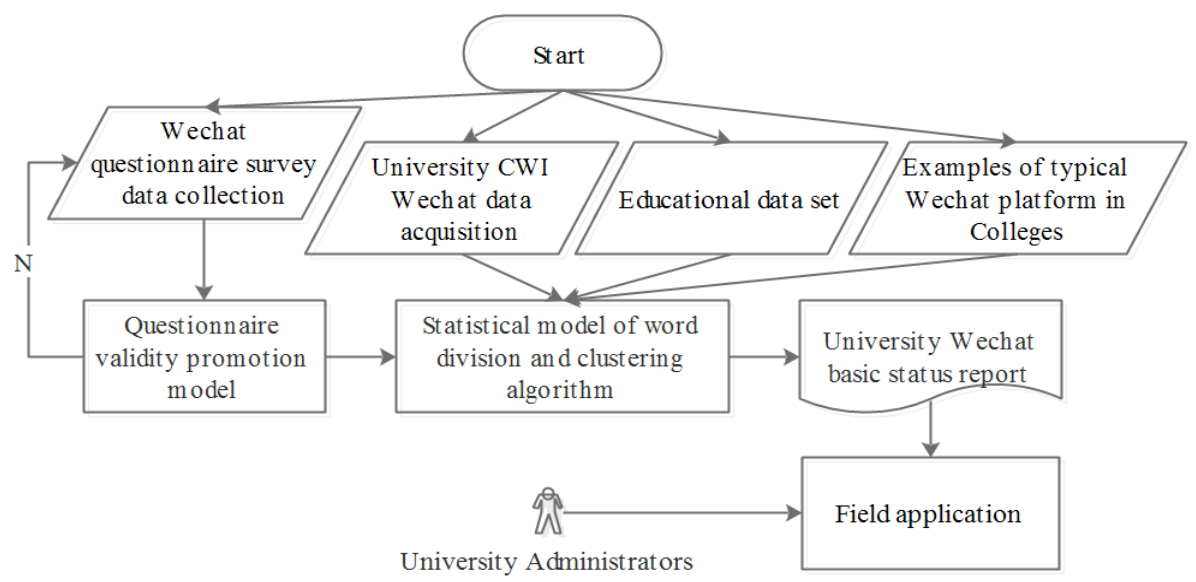

\section{2) Validity control}

\section{a) Test-Retest Reliability}

Control of the same person in the same questionnaire, the more people repeat the test, the more the same questionnaire results will be. Note several problems: a person a questionnaire and no matter when it is only one, the network questionnaire is a IP and an account (QQ, WeChat, micro blog) and can only submit a questionnaire, a unit of a questionnaire.

Because our questionnaire is a classification variable, the Kappa coefficient is used to evaluate the reliability of the heavy test.

$$
\text { Formula: } \mathrm{K}=\left(\mathrm{P}_{\mathrm{a}}-\mathrm{P}_{\mathrm{e}}\right) /\left(1-\mathrm{P}_{\mathrm{e}}\right)
$$
$+\mathrm{d})(\mathrm{c}+\mathrm{d})$
Among them: $P_{a}=(a+d) / n, \quad P_{e}=1 / n 2[(a+c)(a+b)+(b$ $(\mathrm{c}+\mathrm{d})$
$\mathrm{P}_{\mathrm{a}}$ in the form of questionnaire, the actual pass rate, $\mathrm{P}_{\mathrm{e}}$ is the expectation of the qualified rate, the smaller the $\mathrm{K}$ value, the lower the weight of the questionnaire. We have a survey of the distribution of the questionnaire as shown in the following table:

$\mathrm{K}=\left(\mathrm{P}_{\mathrm{a}}-\mathrm{P}_{\mathrm{e}}\right) /\left(\begin{array}{llll}1 & -\mathrm{P}_{\mathrm{e}}\end{array}\right)=\left(\begin{array}{llll}0 & .90 & -0 & .54\end{array}\right) /\left(\begin{array}{lll}1 & -0 & .54\end{array}\right)=0 \quad .78$, The Kappa coefficient is more than $3 / 4$, which indicates that the reliability of the questionnaire and survey is high.

\section{b) Internal Consistency Reliability}

Such as the control of the related degree between various items questionnaire, such as a questionnaire with several from different sides, but investigation is consistent, more appear this kind of circumstance, reduce the questionnaire items related credibility. Pay attention to several problems: give up the low correlation coefficient of individual total score, eliminate the problem of low scoring bias, and eliminate the 
problem of the average number of points close to the range of two level value of the problem, increase the number of questions that reflect the same concept of the same.

Table 2 survey results of the questionnaire survey in the University of WeChat ${ }^{[16]}$

\begin{tabular}{|c|c|c|c|c|c|c|c|}
\hline & & \multicolumn{4}{|c|}{ Measuring weight II } & \multirow{2}{*}{\multicolumn{2}{|c|}{ Total }} \\
\hline & & Sati & ied + & $\begin{array}{l}\text { No } \\
-\end{array}$ & Satisfied & & \\
\hline \multirow{2}{*}{$\begin{array}{l}\text { Measuring } \\
\text { weight I }\end{array}$} & Satisfied + & 30 & $\mathrm{a}$ & 3 & $\mathrm{~b}$ & 33 & $a+b$ \\
\hline & $\begin{array}{l}\text { No } \\
\text { satisfied - }\end{array}$ & 2 & c & 15 & d & 17 & $\mathrm{c}+\mathrm{d}$ \\
\hline Total & & 32 & $a+c$ & 18 & $b+d$ & 50 & $\mathrm{n}$ \\
\hline
\end{tabular}

commonly used Cronbach's alpha to measure the credibility of related items, The $\alpha$ coefficient indicates that the proportion of the total variation of the total variation of the survey results is different ${ }^{[16]}$. That is:

$$
\alpha=\frac{k}{k-1}\left(1-\frac{\sum S_{i}^{2}}{S_{x}^{2}}\right)
$$

Wherein $S_{1}^{2}$ is said to be investigated are the $\mathrm{i}$ answer questions the effectiveness of variance; $S_{x}^{2}$ for all respondents, the answer to all questions of variance; $k$ is the number of items.

We issued questionnaire alpha coefficient is 0.74 , greater than 0.7 (Annually, 1978), is to meet the requirements of credibility associated items.

\section{c) SPSS Reliability Analysis}

The reliability analysis using SPSS software, the operation process is: Analyze $\rightarrow$ Scale $\rightarrow$ Reliability Analysis. The reliability analysis of most of the questionnaire can be realized by this function. In front of the Kappa coefficient analysis we mention the implementation process is: Analyze $\rightarrow$ Descriptive statistics $\rightarrow$ Crosstabs, Finally select the Kappa option. The Alpha option can directly measure items within the association credibility.

3) Collect the key words of WeChat title and optimize the feature

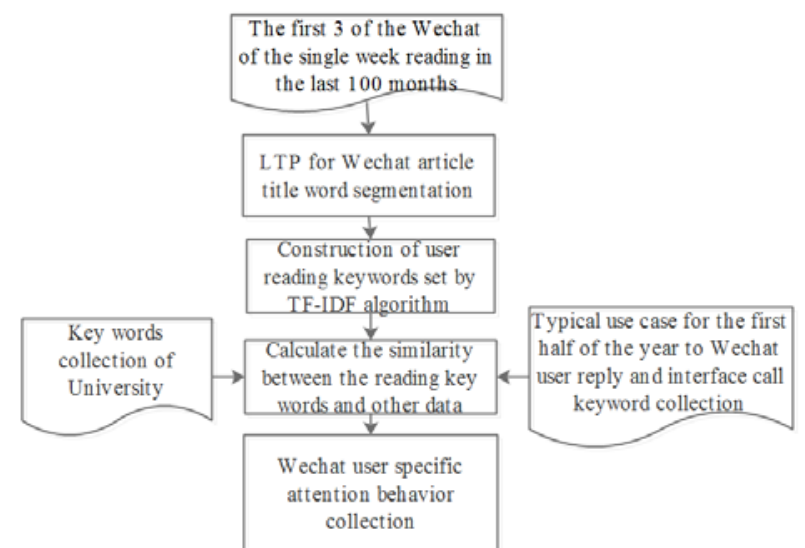

Figure 2 The process of acquisition and calculation of WeChat key words ${ }^{[11]}$

WeChat title describes the content of the article, a high number of WeChat articles can directly reflect the user's behavior. As shown in figure 2: Based on the (WeChat ID: zqbcyol) and Language (WeChat ID: nanfangzhoumo), the article title data of the 3 Official Accounts WeChat, LTP(Language Technology Platform)were used to segment the data set ${ }^{[15]}$. The collected words and typical samples (WeChat reply and call interface data collection) set the use of TF-IDF(term frequency-inverse document frequency) to calculate and filter out the common words, retain the important words after obtaining user behavior data ${ }^{[11]}$.

\section{POPULARIZATION STATUS REPORT}

\section{A. University WeChat user status}

1) WeChat user penetration rate, high viscosity, the relative dependence on WeChat.

In the survey, the high proportion of respondents with the high data rate is shown in Figure 3:Students registered 99\%,Subscribe to the school official WeChat 95\%,Access to campus information first route 95\%,Teachers registered88\%,Pick up the first thing on the phone to browse the WeChat 77\%,More than 100 friends70\%,Open for more than 30 times a day 35\%,More than 5 times in 45 minutes $25 \%{ }^{[4,5,6]}$.

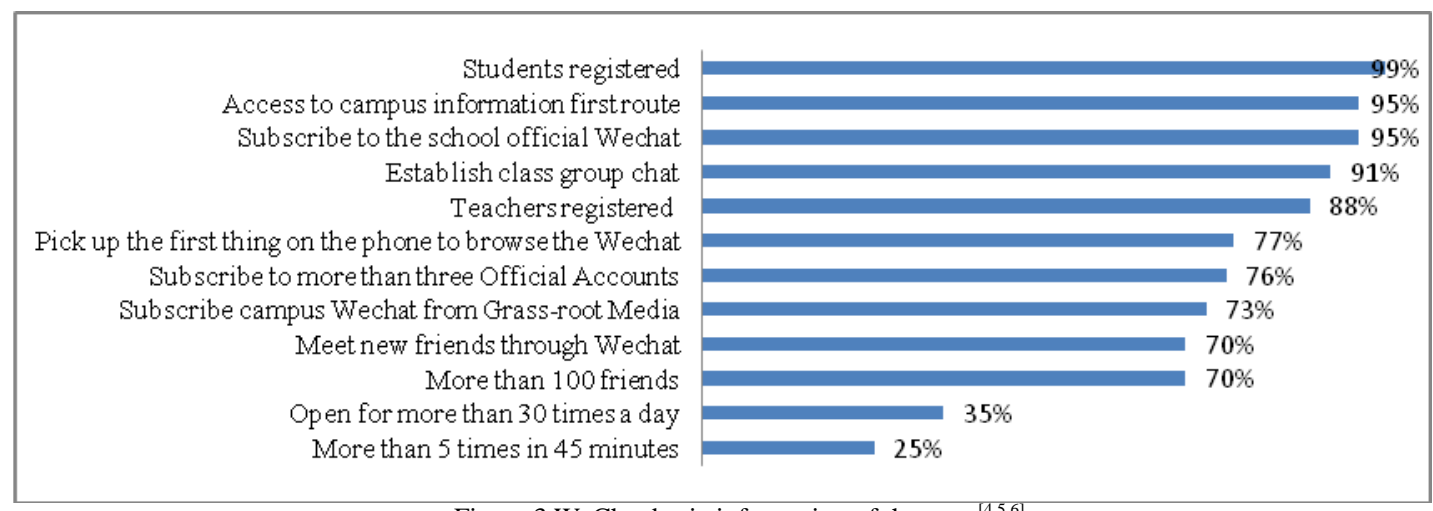

Figure 3 WeChat basic information of the user ${ }^{[4,5,6]}$

2) Because people in the use of the surrounding, but also reflect the better use, coupled with the mobile terminal software and hardware binding, and so on, so now began to register WeChat account.
In the survey, the high proportion of respondents with the high data rate is shown in Figure 4:Crowd around using $85 \%$,Function easy to use $77 \%$,Class group using $55 \%$,School Information received $35 \%$,Because There WeChat on the 
phone 32\%,Accustomed to using Tencent's products $21 \%$, Tencent bundled with the product $11 \%^{[4,5,6]}$.

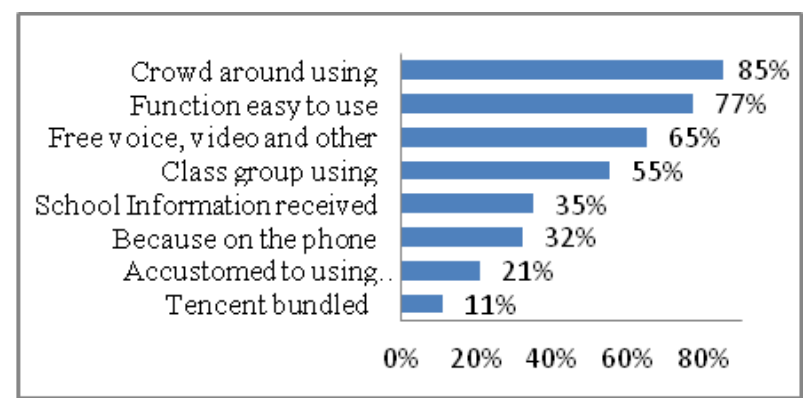

Figure 4 the reason of first usage

3) The school website and the official weibo have WeChat's QR code, online and offline activities to become the main concern of the school's official WeChat.

In the survey, the high proportion of respondents with the high data rate is shown in Figure 5:Through official website $53 \%$,Through official weibo 51\%,Through online and offline activities $42 \%$, Recommended by the Teachers and students 42\%,Through paper material 35\%,Mobile applications through campus $14 \%$.

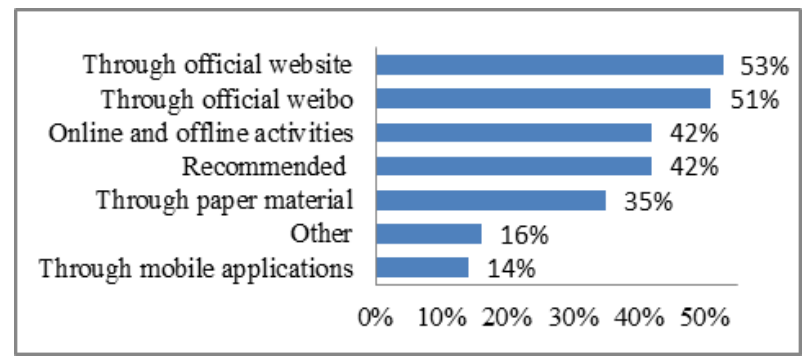

Figure 5 the way to aquire the school's offical WeCha

4) For Chinese College WeChat users to use WeChat is mainly used to communicate dialogue and take care of the relationship between friends, with WeChat to learn and do ecommerce, relatively small.

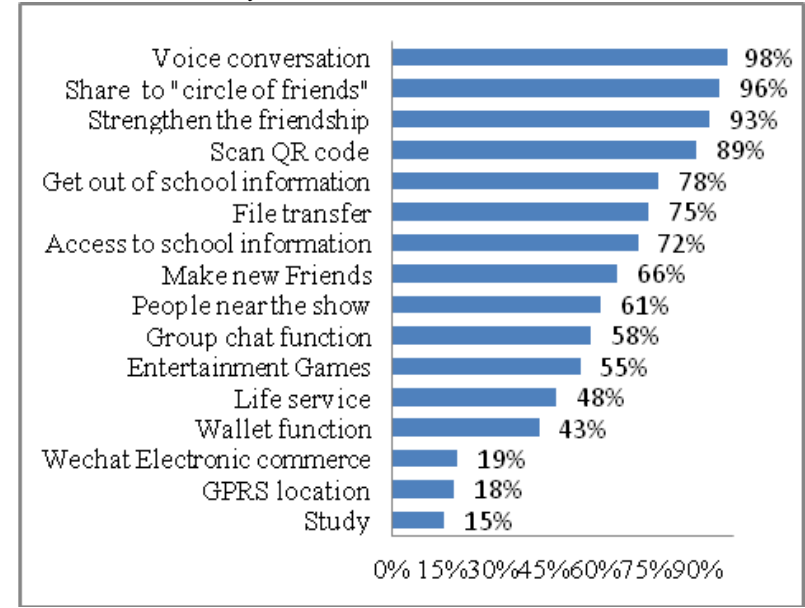

Figure 6 what do the users do with WeChat ${ }^{[4,5,6]}$

In the survey, the high proportion of respondents with the high data rate is shown in Figure 6:Voice conversation 98\%, Share and subscribe to "circle of friends"96\%,Strengthen the friendship 93\%, Scan QR code 89\%, Get out of school information $78 \%$, File transfer $75 \%$, Access to school information 72\%, Make new Friends 66\%, People near the show 61\%, Group chat function 58\%, Entertainment Games $55 \%$, Life service 48\%, Wallet function $43 \%$, WeChat Electronic commerce 19\%, GPRS location 18\%, Study $15 \%{ }^{[4,5,6]}$.

5) In Chinese colleges and universities WeChat use of the peak period of the general appearance in the evening 19:0023:00 and 12:00-14:00 pm.

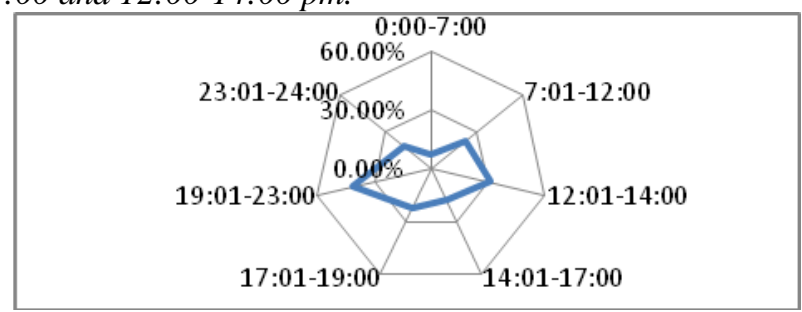

Figure 7 time being willing to receive message

In Chinese colleges and universities WeChat use of the peak period of the general appearance in the evening 19:0023:00 and 12:00-14:00 pm. Survey found that the proportion of users using time as shown in figure 7:0:00-7:00 is 6.9\%, $7: 01-12: 00$ is $23 \%, 12: 01-14: 00$ is $31 \%, 14: 01-17: 00$ is $18 \%$, $17: 01-19: 00$ is $22 \%, 19: 01-23: 00$ is $41 \%, 23: 01-24: 00$ is $18 \%$.

\section{B. WeChat operation in Colleges and Universities}

1) The opening rate of the micro channel public number in Chinese colleges and universities, and most of the micro channel as the main media, WeChat digital campus application is relatively low.

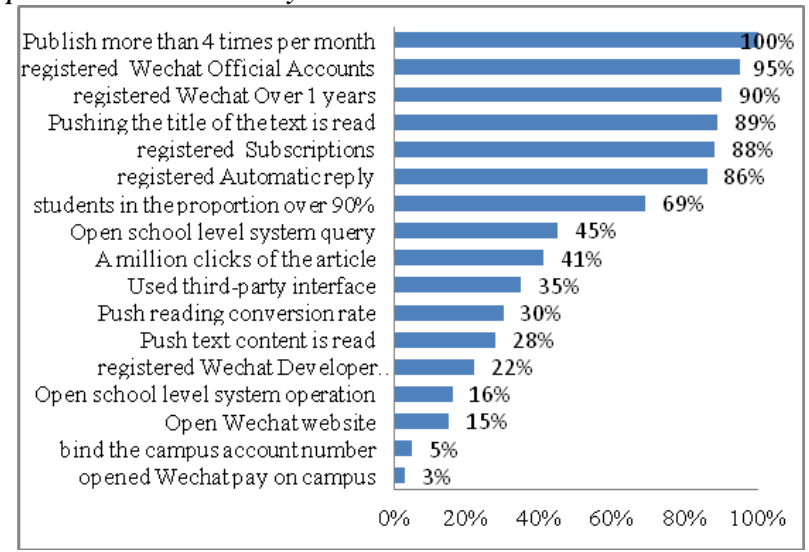

Figure 8 University official WeChat popularization[4,5,6]

The proportion of data in the survey object is shown in Figure 8:Publish more than 4 times per month 100\%, registered WeChat Official Accounts 95\%, registered WeChat Over 1 years $90 \%$, Pushing the title of the text is read $89 \%$, registered Subscriptions 88\%, registered Automatic reply $86 \%$, Fans students in the proportion of more than $9 / 1069 \%$, Open school level system query $45 \%$, There are a million clicks of the article 41\%, Used third-party interface 35\%, Push the article reading conversion rate $30 \%$, Push text content is read 28\%, registered WeChat Developer function 22\%, Open school level system operation 16\%, Open WeChat website $15 \%$, Use WeChat to bind the campus account number $5 \%$, opened WeChat pay on campus $3 \%{ }^{[4,5,6]}$. 
2) Chinese University WeChat Official Accounts fans are mainly: Enrolment Student 、 Alumnus \& Alumna 、 Educational Personnel, parents, Cooperative units and Other.

As shown in figure 9:Enrolment Student 69\%,Alumnus \& Alumna 16\%,Educational Personnel 7\%,parents $3 \%$,Cooperative units $1 \%$,Other $4 \%$.

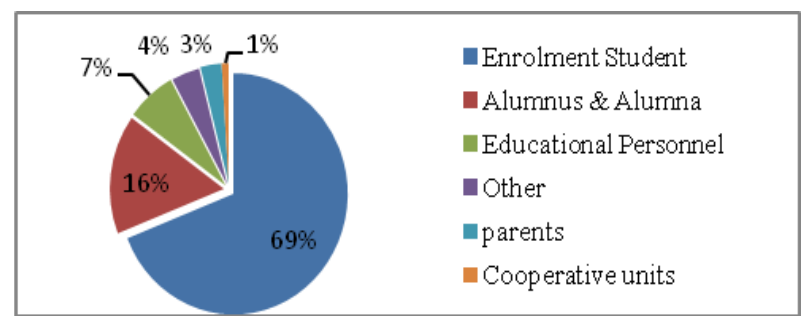

Figure 9 University WeChat Official Accounts fans ingredients

3) The higher the WeChat Official Accounts in Chinese colleges and universities in the words of the high degree of concern:Course list, Admission, Club, Achievement, Get a job, Holiday, All-in-One Card Syste , Course Selection...

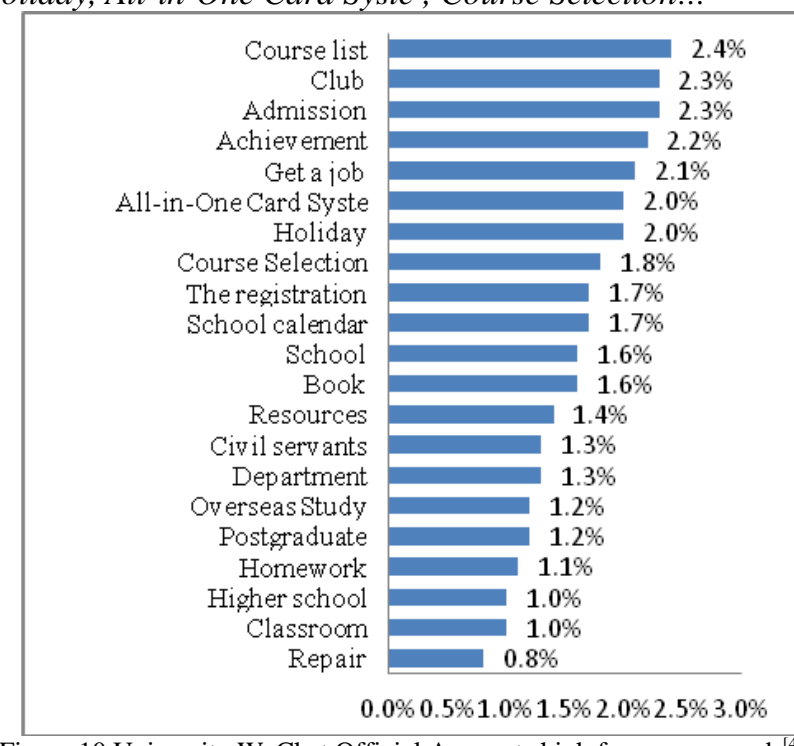

Figure 10 University WeChat Official Accounts high frequency words ${ }^{[4,5,6]}$

The frequency of the survey is shown in Figure 10:Course list 2.4\%, Admission2.3\%, Club2.3\%, Achievement $2.2 \%$, Get a job 2.1\%, Holiday 2\%, All-in-One Card Syste 2\%, Course Selection 1.8\%, School calendar 1.7\%, The registration 1.7\%, Book 1.6\%, School 1.6\%, Resources 1.4\%, Department 1.3\%, Civil servants 1.3\%, Postgraduate 1.2\%, Overseas Study 1.2\%, Homework 1.1\%, Classroom 1\%, Higher school 1\%, Repair0.8\% ${ }^{[4,5,6]}$.

4) Convenient and personalized service, strong transmission ability, high popularity and dependability, complete basic software and hardware...Become the biggest advantage of the campus WeChat digital platform.

In the survey, the high proportion of respondents with the high data rate is shown in Figure 11:Convenient and personalized service $88 \%$, strong transmission ability $84 \%$, high popularity and dependability $84 \%$, complete basic software and hardware $83 \%$, easy acceptance $82 \%$, Low investment cost $82 \%$, fine interaction $78 \%$, unlimited message receiving $73 \%$, Stable and reliable platform 68\%, easy to acquire users' demend 66\%, high reliability 66\%, feasible management $57 \%$, complete supporting facility $56 \%$, provide reference for the development of other areas 55\%, Service based on LBS $48 \%$, easy exploitation $42 \%$, WeChat open API rich $41 \%$.

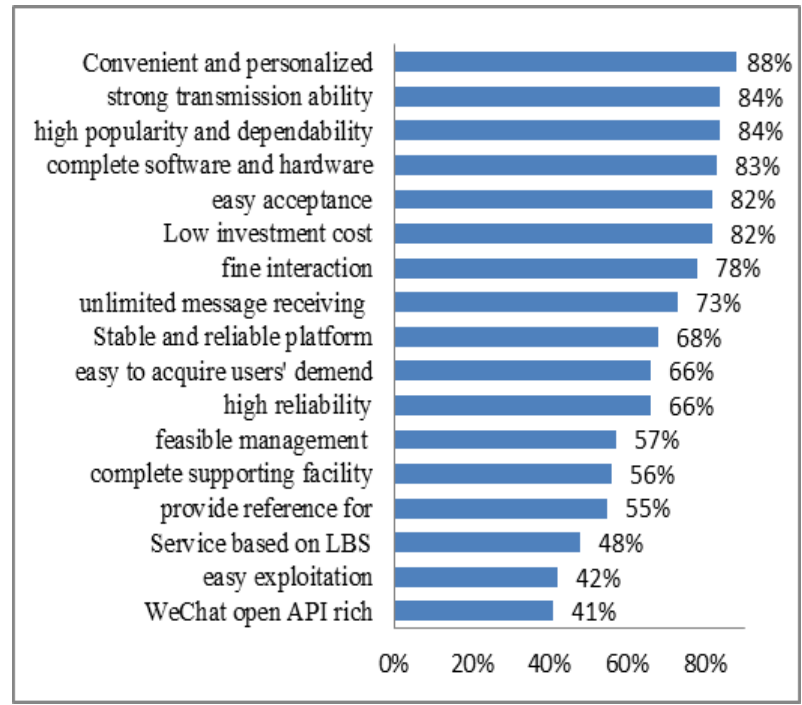

Figure 11 superiority of campus WeChat public platform

5) Lack of talent, Elack of education solution, $A A P$ isolation, insufficient cooperation of department, Tencent insufficient open of API ...Become the biggest obstacle to the construction of micro channel digital campus platform.

In the survey, the high proportion of respondents with the high data rate is shown in Figure 12:Lack of talent 68\%, lack of education solution 57\%, AAP isolation 46\%, insufficient cooperation of department 37\%, insufficient open of API 34\%, revealing of campus resources $24 \%$, WeChat and campus system docking difficult $23 \%$, privacy revealing of users $21 \%$, lack of infrastructure $14 \%$, less attention from schools $12 \%$.

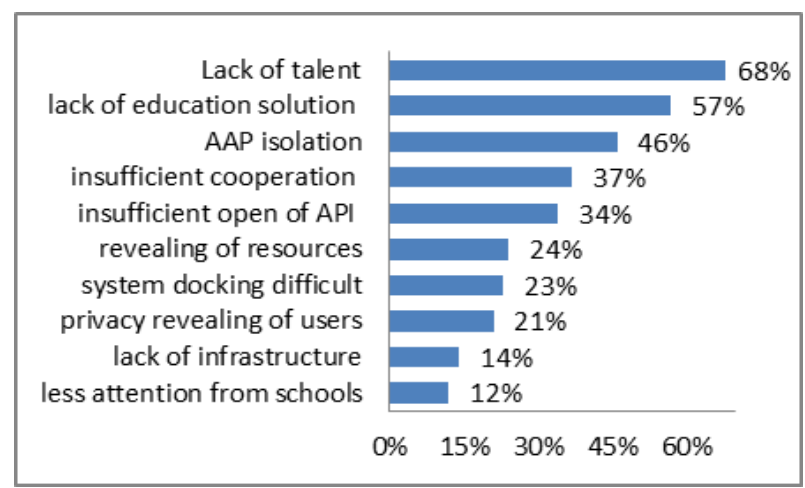

Figure 12 the difficulty of consructing digitizing campus WeChat

6) Push message, Auto reply user, Combined with traditional media, Online and offline activities, Vote...Become the main method of WeChat operation in Colleges and universities.

In the survey, the high proportion of respondents with the high data rate is shown in Figure 13:Push message 100\%,Auto reply user $86 \%$,Combined with traditional media 79\%,Online and offline activities 73\%,Vote 67\%,Human Service 
33\%,Default version information 25\%,Comment 21\%,Build WeChat website $15 \%$,Combined with the school system $14 \%$.

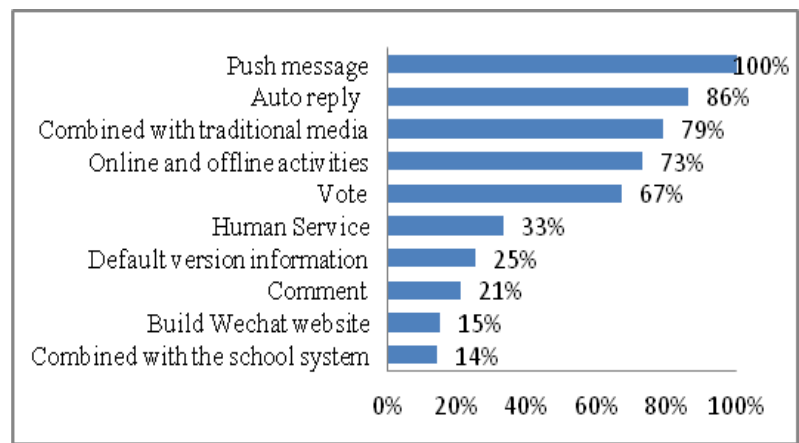

Figure 13 the main method of running WeChat platform in Colleges and Universities

7) University users want the school to open the WeChat:Recharge All-in-One Card, Query results, Borrow books, Query schedule list...

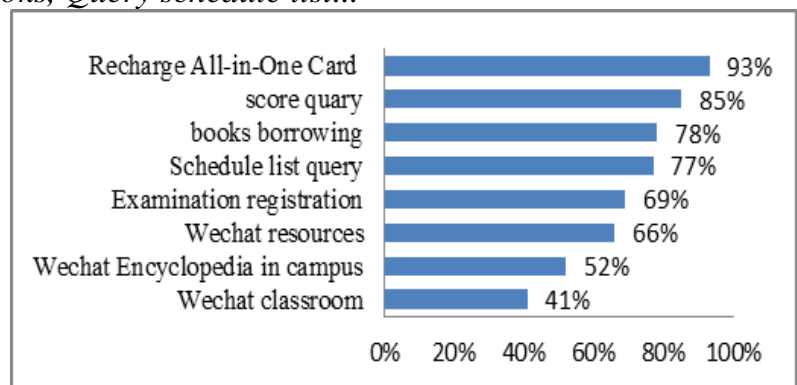

Figure 14 tendency of application and requirement in campus

In the survey, the high proportion of respondents with the high data rate is shown in Figure 14:Recharge All-in-One Card 93\%, score quary 85\%, books borrowing 78\%, Schedule list query 77\%,Examination registration 69\%,WeChat resources 66\%, WeChat Encyclopedia in campus $52 \%$,WeChat classroom $41 \%$.

\section{CONCLUSION}

The author of this article and its team members, through the collection of a questionnaire 267136 use WeChat acquisition simulator nearly 2GB data capture, compare the authority of the combination of domestic universities WeChat dissemination leaderboard data (China Youth Daily, Southern Weekend) and key terminology in the field of college education collection. Through the LPD (language technology platform) words Processing ${ }^{\text {[15] }}$ and TF-IDF (term frequencyinverse document frequency) algorithm similar calculation ${ }^{[11]}$ and assemble class data mining models, a descriptive statistics and inference of statistics have been reported. The report to a large extent reflects the objective facts, real and effective and can serve as a digital campus building in colleges and universities, and management.

Because of the domestic and international popularity of colleges and universities on the study of the WeChat report relatively little, Tencent official platform has not fully shared WeChat colleges and universities based on statistical data, is so the results of the analysis will have a certain impact on. That would be required in the future to further cooperate with the Tencent official cooperation, efforts to develop WeChat studies on the characteristics of the user community.

\section{References}

[1] National Bureau of Statistics. Statistical bulletin of the national economic and social development of the PRC in 2014 [R]. http://www.stats.gov.cn, 2015.

[2] Ministry of Education. national list of colleges and Universities of the PRC in 2014 [R]. http://www.moe.gov.cn, 2015.

[3] Ministry of Education. Education statistics of the PRC in 2014 [R]. http://www.moe.gov.cn, 2015.

[4] Tencent 2015 first quarter results report [R]. Tencent data,2015

[5] China Youth Daily WeChat[OL].WeChat ID:zqbcyol.

[6] Southern Weekend WeChat [OL].WeChat ID: nanfangzhoumo.

[7] CNNIC. 2014 China social class Application User Behavior Research Report[R]. http://www.cnnic.cn.2014(8).

[8] CNNIC. Statistical report on the development of the 36th China Internet Network [R]. http://www.cnnic.cn.2015(7).

[9] Tencent .Interpretation of the correct posture of the WeChat user data report [R]. Tencent data,2015(10).

[10] Harbin Institute of Technology. Language Technology Platform[OL].http://www.ltp-cloud.com.

[11] Gyarmati, L., \& Trinh, T. A. (2010). Measuring user behavior in online socialnetworks. Network, IEEE, 24(5), 26-31

[12] Che Hui Lien,Yang Cao.Examining WeChat users' motivations, trust, attitudes, and positive word-of-mouth: Evidence from China.Computers in Human Behavior, 2014, 41:104-111.

[13] Valenzuela, S., Park, N., \& Kee, K. F. (2009). Is there social capital in a social networksite?: Facebook use and college students' life satisfaction, trust, andparticipation1. Journal of Computer-Mediated Communication, 14(4), 875-901.

[14] Francesco Buccafurri , Gianluca Lax, Serena Nicolazzo, Antonino Nocera.Comparing Twitter and Facebook user behavior: Privacy and otheraspects.Computers in Human Behavior, 52 (2015) 87 - 95

[15] Gina Masullo Chen.Tweet this: A uses and gratifications perspective on how active Twitter use gratifies a need to connect with others.Computers in Human Behavior, 2011, 27(2):755-762.

[16] ZENG Wu-yi, HUANG Bing-yi.Analysis on the Rel iability and Validity of Questionnaire Statistics \& Information Forum,Vol.20 No.6Nov, 2005.

[17] ZHAO Yu, SHAO Bilin, BIAN Genqing, SONG Dan. Prediction of retweeting behavior for imbalanced dataset in microblogs. Journal of Computer Applications, doi: 10.11772 /j.issn.1001-9081.2015,07,1959.

[18] Zlatolas, L. N., Welzer, T., Hericko, M., \& Holbl, M. (2015). Privacy antecedents for SNS self-disclosure: The case of Facebook. Computers in Human Behavior, 45,158 - 167.

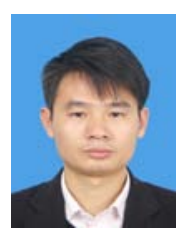

Li You-Hong, Male, born in 1983, master, lecturer, Information system project management division, Experimentalist, China Computer Federation (CCF) member, His current research interests include digital campus, Social network computing, Internet Plus, big data mining. Email:280069157@qq.com. 